\title{
Use of Indocyanine Green (ICG) in Hepatology
}

\author{
Kim Frisch ${ }^{1}$ and Susanne Keiding ${ }^{1,2 *}$ \\ ${ }^{1}$ Department of Nuclear Medicine \& PET Centre, Aarhus University Hospital, Denmark \\ ${ }^{2}$ Department of Hepatology \& Gastroenterology, Aarhus University Hospital, Denmark
}

Submission: October 10, 2020; Published: November 09, 2020

*Corresponding author: Susanne Keiding, Department of Nuclear Medicine \& PET Centre, Aarhus University Hospital J119, DK-8200 Aarhus, Denmark

\begin{abstract}
The organic anion indocyanine green (ICG) is eliminated solely via hepatobiliary excretion. Consequently, ICG is used to measure the hepatic blood flow by a constant intravenous infusion of ICG, with measurements of ICG blood concentrations in an artery and a hepatic vein, and calculation by Fick's principle according to simple mass conservation. Secondly, ICG is used to estimate various hepatic clearances, using constant intravenous infusion or bolus injection of ICG and measurements of concentrations of ICG in peripheral blood. These clearance values reflect hepatic blood flow and hepatobiliary excretory function depending on hepatic removal kinetics and systemic blood circulation at the (patho)physiological condition studied. Third, during recent years, a simple ICG 15-minute retention test (ICG-r15) is developed, using intravenous bolus injection of ICG, measurements of ICG concentration in peripheral blood after 15 minutes, and calculation of percentage ICG of the dose injected which is retained in the body. The ICG-r15 test, which is primarily used to assess the hepatobiliary excretory function but also a wide range of other conditions, is however based on dubious physiological assumptions. In this review, we go through these various applications of ICG measures in hepatology, focusing on physiological background of the tests and their use in studies of liver hemodynamics during normal conditions and liver diseases.
\end{abstract}

Keywords: Hepatic blood flow; Hepatic clearance; Hepatic excretory function; Liver diseases; Liver removal kinetics

\section{Introduction}

Indocyanine green (ICG) is a synthetic organic anion that is bound to lipoproteins in plasma [1] and as such, ICG is transported efficiently from the sinusoidal blood within the liver into the hepatocytes [2,3]. From the hepatocytes, it undergoes active transport into the biliary canaliculi [3]. Hepatobiliary excretion comprises $100 \%$ of un-changed ICG elimination from the body. These observations constitute the background for the use of ICG for measurements of the hepatic blood flow rate as well as the intrinsic hepatic clearance, the latter as a measure of the hepatobiliary excretory capacity. These classical procedures require measurements of ICG concentration in blood samples from an artery and a liver vein. Simplified measures with the need for only peripheral venous blood samples have been developed, which methods, however, are not based on sound physiological principles. Consequently, their clinical applications are dubious. We here take the opportunity to go rigorously through the various methodologies and clinical applications of ICG in hepatology.

\section{Methodologies and Clinical Applications}

\section{Hepatic Blood Flow - Constant ICG Infusion - Fick's Principle}

ICG distributes in the extended plasma volume [4] and during a constant intravenous ICG infusion rate of about $0.13 \mu \mathrm{mol} / \mathrm{min}$ to a human subject, $95 \%$ or more approximation to steady state blood concentrations is achieved after 90 minutes [5]; at higher infusion rates, the time to reach steady state is longer. All infused ICG is eliminated by the liver and at steady state-concentrations, we have

$$
\mathrm{F}=\text { Infusion rate } /(\mathrm{A}-\mathrm{V})
$$

where $\mathrm{F}$ is the hepatic blood flow (L blood/min) and A and $\mathrm{V}$ are mean blood concentrations of ICG in a peripheral artery and a hepatic vein, respectively ( $\mu \mathrm{mol} / \mathrm{L}$ blood). In practice, we use a 15-60 min measurement period with four to five pairs of plasma 
samples. ICG concentration is determined in plasma either by spectrophotometry [6] or HPLC [4] and corrected for measured arterial hematocrit values to achieve blood concentrations.

This flow measurement depends on mass conservation and achievement of good approximation to steady state blood concentrations of ICG. It is independent of the hepatic elimination kinetics of ICG. We calculate the deviation from steady state as the linear slope of the time course of the arterial blood concentration of ICG multiplied with 5\% of the body weight under the assumption of this volume equals the volume of distribution of ICG during the measurement period ( $\mu \mathrm{mol} / \mathrm{min})$. If necessary, measured infusion rate may be corrected accordingly [5]; in our hands, the correction for non-steady state amounts to less than $1 \%$ of the infusion rate. The method shows good agreement with electromagnetic technique in dogs [7] and anesthetized pigs (S. Keiding, unpublished data, 2020). Figure 1 shows an example of the ICG plasma concentration measurements for estimation of the hepatic blood flow in a human subject.

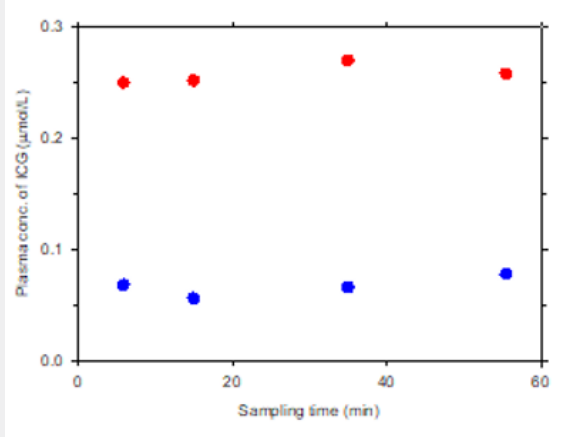

Figure 1. Example of how the hepatic blood flow can be measured by constant intravenous infusion of ICG and calculation according to Fick's principle of mass conservation. Time course of plasma concentrations of ICG in a radial artery $\left({ }^{\circ}\right)$ and a hepatic vein $(\bullet)$ during constant intravenous infusion of ICG of $0.13 \mu \mathrm{mol} / \mathrm{min}$, initiated $90 \mathrm{~min}$ before start of sampling in a 67 year patient with primary biliary cholangitis.
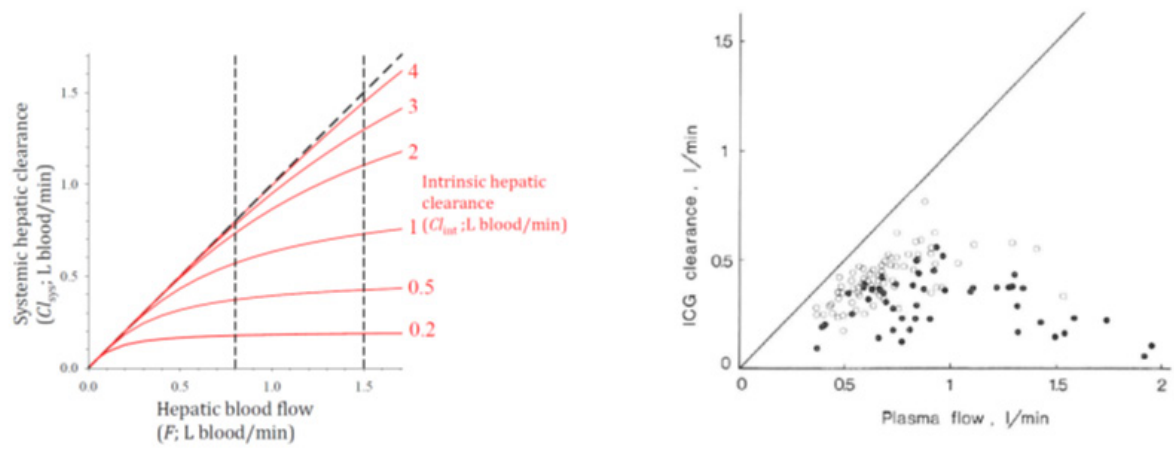

Figure 2: Left panel: Relationship between $\mathrm{Cl}_{\text {sys }}$ and $\mathrm{F}$ for various values of $\mathrm{Cl}_{\text {int }}$ according to $\mathrm{Eq}$. $3 \mathrm{~b}$.

Right panel: Relationship between systemic hepatic plasma clearance of ICG $\left(\mathrm{Cl}_{\mathrm{sys}}\right)$ and plasma flow $(\mathrm{F})$ in subjects without liver disease $(\circ)$ and patients with liver disease $(\cdot)$ (from ref 5$)$.

Here we give two examples of clinical application of the method: In patients examined for abdominal pain, the estimated F discriminated well between patients with functional important stenosis of abdominal arteries or no stenosis [8]. Recently, we showed that the PET-determined unidirectional clearance of the conjugated bile acid tracer [N-methyl-11C]cholylsarcosine (11C-CSar) was determined by the hepatic blood flow - and not the hepatocyte plasma membrane transport capacity for 11C-CSar - in patients with primary biliary cholangitis [9].

\section{Hepatic Clearances Measured by Constant ICG Infusion}

Two first-order hepatic clearance concepts are defined according to the sinusoidal perfusion model of uptake of substrates from blood flowing through the intact liver [10-14]: First, the flow-independent intrinsic hepatic clearance $\mathrm{Cl}_{\text {int }}$ of ICG (L blood/ $\mathrm{min}$ ) is a measure of the maximal hepatobiliary excretory function (corresponding to Vmax/Km for enzymatic reactions; 10,11):

$$
\mathrm{Cl}_{\text {int }}=\text { Infusion } /((\mathrm{A}-\mathrm{V}) / \ln (\mathrm{A} / \mathrm{V}))=-\mathrm{F} \ln (1-\mathrm{E})
$$

where $\mathrm{E}=(\mathrm{A}-\mathrm{V}) / \mathrm{A}$ is the hepatic extraction fraction.

Second, the flow-dependent systemic hepatic clearance, $\mathrm{Cl}_{\text {sys }}$ of ICG (L blood/min), measured with respect to the systemic blood concentration of ICG (here A) [10-12]:

$$
\begin{aligned}
& \mathrm{Cl}_{\text {sys }}=\text { Infusion } / \mathrm{A}=\mathrm{F}(\mathrm{A}-\mathrm{V}) / \mathrm{A}=\mathrm{F} \mathrm{E} \\
& \mathrm{Cl}_{\text {sys }}=\mathrm{F}\left(1-\mathrm{e}^{- \text {Clint }} / \mathrm{F}\right) .
\end{aligned}
$$

Figure 2 shows the relationship between $\mathrm{Cl}_{\text {sys }}$ and $\mathrm{F}$ for various values of $\mathrm{Cl}_{\text {int }}$ according to $\mathrm{Eq}$. $3 \mathrm{~b}$ and the corresponding data points for 86 persons with no liver disease and 52 patients with cirrhosis [5]. For $\mathrm{Cl}_{\text {int }}>>\mathrm{F}$, the liver remove nearly all substrate 
supplied by the blood stream, and $\mathrm{Cl}_{\text {sys }}$ approximates $\mathrm{F}\left(\mathrm{Cl}_{\text {sys }}\right.$ is flow-determined); for $\mathrm{Cl}_{\text {int }}<<\mathrm{F}$, the hepatic removal is determined by the hepatic removal capacity and $\mathrm{Cl}_{\text {sys }}$ approximates $\mathrm{Cl}_{\text {int }}$ [11]. The figures show that in general, $\mathrm{Cl}_{\text {int }}$ is larger in healthy subjects than in patients with liver disease. However, although $\mathrm{Cl}_{\text {sys }}$ approximates $\mathrm{F}$ better for the healthy subjects than for the patients with liver disease, the variation is large, ranging from 30 - $90 \%$. Consequently, the use of $\mathrm{Cl}_{\text {sys }}$ as an approximation to $\mathrm{F}$ is not justified, even not in the healthy subjects. Similarly, although $\mathrm{Cl}_{\text {sys }}$ approximates $\mathrm{Cl}_{\text {int }}$ better for patients with liver disease than for the healthy subjects, the variation is large, ranging from 60 $90 \%$, and the use of $\mathrm{Cl}_{\text {sys }}$ as an approximation to $\mathrm{Cl}_{\text {int }}$ is not justified, even not in patients with liver impairment.

In passing, we may notice that the clearance-requirement of hepatic first-order kinetics for the biliary excretion of ICG was fulfilled at the infusion doses used in the above-mentioned studies [15].

\section{Hepatic Clearance Measured by Bolus Injection of ICG}

In order to simplify assessment of the hepatobiliary excretory function, some authors use bolus intravenous injection of ICG and calculation of the systemic hepatic clearance $\left(\mathrm{Cl}_{\text {sys }}\right)$ from the time course of the decay of the plasma concentration of ICG in peripheral blood; no use of hepatic vein blood samples. However, not only does $\mathrm{Cl}_{\text {sys }}$ not approximate $\mathrm{Cl}_{\text {int }}$ adequately (as shown above), but also the use of bi-exponential curve-fitting of the decay of the plasma ICG concentration to estimate clearance will unavoidably be biased of varying early time-dependent distribution of ICG in the extracellular volumes [14]. Moreover, also effects of the hepatic blood flow are ignored. Consequently, clinical use of the ICG bolus procedure is not justified.

\section{ICG-r15 test}

During recent years, the ICG 15-minute retention test (ICG-r15) is increasingly used as a measure of hepatobiliary excretory function [16]. This method comprises intravenous bolus injection of ICG, measurements of ICG concentration in peripheral plasma after 15 minutes, and calculation of percentage ICG of the dose injected which is retained in the body. The lower the percentage retained, the better the hepatobiliary excretory function. The test is used for pre-operative prognostic measure of the remnant liver excretory function after liver resection [16-18] but also as a marker of portal hypertension [19-21] and a wide range of other applications. A recent study comparing $\mathrm{Cl}_{\text {sys }}$ from constant intravenous infusion with the ICG-r15 [21] finds good negative correlation between the two measures. However, this finding does not overrule the fundamental biases within the use of $\mathrm{Cl}_{\text {sys' }}$, being highly dependent on both the hepatobiliary excretory function and the hepatic blood flow as mentioned in the foregoing section.

\section{Conclusion}

ICG infusion-based estimates of the hepatic blood flow, using Fick's principle, and of the hepatobiliary excretory capacity, using the intrinsic hepatic clearance, are based on basic physiological principles, experimentally validated, and proven clinically and experimentally useful. In contrast, neither the systemic hepatic clearance from ICG infusion or bolus, nor the 15 min retention test, are justified for (patho)-physiological studies or clinical applications in hepatology.

\section{References}

1. Ott P, Bass L, Keiding S (1997) Hepatic ICG removal in the pig depends on plasma protein and hematocrit: Evidence of sinusoidal binding disequilibrium and unstirred water layer effects. Hepatology 26(3): 679-690.

2. Keiding S, Ott P, Bass L (1993) Enhancement of unbound clearance of ICG by plasma protein, demonstrated in human subjects and interpreted without assumption of facilitating structures. J Hepatol 19(3): 327-344.

3. Stieger B (2011) The role of the sodium-taurocholate cotransporting polypeptide (NTCP) and of the bile salt export pump (BSEP) in physiology and pathophysiology of bile formation. Handb Exp Pharmacol 201: 205-259.

4. Ott P, Keiding S, Bass L (1993) Plasma elimination of indocyanine green in the intact pig after bolus injection and during constant infusion: Comparison of spectrophotometry and HPLC for concentration analysis. Hepatology 18(6): 1504-1515.

5. Skak C, Keiding S (1987) Methodological problems in the use of indocyanine green to estimate hepatic blood flow and ICG clearance in man. Liver 7: 155162.

6. Nielsen NC (1963) Spectrophophometric determination of indocyanine green in plasma especially with a view to an improved correction for blank density. Scand J Clin Lab Invest 15(6): 613-621.

7. Teranaka M, Schenk WG (1977) Hepatic blood flow measurement. A comparison of the indocyanine green and electromagnetic techniques normal and abnormal flow states in the dog. Ann Surg 185(1): 58-63.

8. Hansen HJ, Engell HC, Ring-Larsen H, Ranek L (1977) Splanchnic blood flow in patients with abdominal angina before and after arterial reconstruction. A proposal for a diagnostic test. Ann Surg 186(2): 216220.

9. Kjærgaard K, Frisch K, Sørensen M, Munk OL, Hofmann AF, et al. (2021) Obeticholic acid improves hepatic bile acid excretion in patients with primary biliary cholangitis. J Hepatol 74: 58-65.

10. Bass L, Keiding S, Winkler K, Tygstrup N (1976) Enzymatic elimination of substrates flowing through the intact liver. J theor Biol 61(2): 393 409.

11. Winkler K, Bass L, Keiding S, Tygstrup N (1979) The physiologic basis of clearance measurements in hepatology. Scand J Gastroenterol 14(4): 439448.

12. Keiding S (1987) Hepatic clearance and liver blood flow. Editorial. J Hepatol 4(3): 393398.

13. Keiding S, Skak C (1988) Methodological limitations of the use of intrinsic hepatic clearance of ICG as a measure of liver cell function. Eur J Clin Invest 18: 507-511.

14. Keiding S (1991) Dynamic aspects of hepatic removal of circulating substances. In: McIntyre N, Ben-hamou J P, Bircher J, Rizzetto M, Rodes J (eds) Oxford Textbook of Clinical Hepatology. Oxford University Press, pp. 78-87. 
15. Ott P, Bass L, Keiding S (1996) The kinetics of continuously infused indocyanine green in the pig. J Pharmacokinetics Biopharm 24(1): 1944 .

16. Imamura H, Sano K, Sugawara Y, Kokudo N, Makuuchi M (2005) Assessment of hepatic reserve for indication of hepatic resection decision tree incorporating indocyanine green test. J Hepatobiliary Pancreat Surg 12(1): 16-22.

17. Mizumoto M, Oshiro Y, Okumura T, Fukuda K, Fukumitsu N, et al. (2014) Association between pretreatment retention rate of indocyanine green 15 min after administration and life prognosis in patients with HCC treated by proton beam therapy. Radiother Oncol 113(1): 54-59.

18. Feng K, Yan J, Li X, Xia F, Ma K, et al (2012) A randomized controlled trial of radiofrequency ablation and surgical resection in the treatment of small hepatocellular carcinoma. J Hepatol 57(4): 794-802.
19. Lisotti A, Azzaroli F, Buonfiglioli F, Montagnani M, Cecinato P, et al (2014) Indocyanine green retention test as a noninvasive marker of portal hypertension and esophageal varices in compensated liver cirrhosis. Hepatology 59: 643-650.

20. Pind ML, Bendtsen F, Kallemose T, Møller S (2016) Indocyanine green retention test (ICG-r15) as a noninvasive predictor of portal hypertension in patients with different severity of cirrhosis. Eur J Gastroenterol Hepatol 28(8): 948-954.

21. Møller S, la Cour Sibbesen E, Madsen JL, Bendtsen F (2019) Indocyanine green retention test in cirrhosis and portal hypertension: Accuracy and relation to severity of disease. J Gastroenterol Hepatol 34(6): 1093-1099.

\section{Your next submission with JuniperPublishers will reach you the below assets}

- Quality Editorial service

- Swift Peer Review

- Reprints availability

- E-prints Service

- Manuscript Podcast for convenient understanding

- Global attainment for your research

- Manuscript accessibility in different formats ( Pdf, E-pub, Full Text, audio)

- Unceasing customer service

Track the below URL for one-step submission https://juniperpublishers.com/online-submission.php 